\title{
Dose-response relationship in cyclophosphamide-treated B-cell lymphoma xenografts monitored with $\left[{ }^{18}\right.$ F]FDG PET
}

\author{
Lieselot Brepoels • Marijke De Saint-Hubert • \\ Sigrid Stroobants • Gregor Verhoef • Jan Balzarini • \\ Luc Mortelmans • Felix M. Mottaghy
}

Received: 26 August 2009 /Accepted: 13 April 2010/Published online: 12 May 2010

(C) Springer-Verlag 2010

\begin{abstract}
Purpose Although $\left[{ }^{18} \mathrm{~F}\right] \mathrm{FDG}$ PET can measure therapy response sooner and more accurately than morphological imaging techniques, there is still some debate as to whether $\left[{ }^{18} \mathrm{~F}\right] \mathrm{FDG}$ uptake really reflects changes in the viable cell fraction. In this study changes in $\left[{ }^{18} \mathrm{~F}\right] \mathrm{FDG}$ uptake were investigated in a lymphoma model at several time-points
\end{abstract}

L. Brepoels and M. De Saint-Hubert contributed equally to the study.

L. Brepoels · M. De Saint-Hubert · L. Mortelmans ·

F. M. Mottaghy

Department of Nuclear Medicine,

University Hospital Gasthuisberg Leuven,

Leuven, Belgium

S. Stroobants

Department of Nuclear Medicine, University Hospital Antwerpen,

Edegem, Belgium

G. Verhoef

Department of Hematology,

University Hospital Gasthuisberg Leuven,

Leuven, Belgium

J. Balzarini

Department of Microbiology and Immunology, KU Leuven,

Leuven, Belgium

F. M. Mottaghy

Klinik für Nuklearmedizin,

Universitätsklinikum der RWTH Aachen,

Aachen, Germany

F. M. Mottaghy $(\varangle)$

Klinik für Nuklearmedizin,

Universitätsklinikum der RWTH Aachen,

Pauwelsstraße 30,

52074 Aachen, Germany

e-mail: fmottaghy@ukaachen.de after treatment and with different doses of chemotherapy. Data were analysed in terms of several parameters.

Methods SCID mice were subcutaneously inoculated with $5 \times 10^{6}$ Daudi cells in the right thigh. One group was not treated (control group). The other groups received cyclophosphamide $75 \mathrm{mg} / \mathrm{kg}$ (low-dose group), $125 \mathrm{mg} / \mathrm{kg}$ (medium-dose group) and $175 \mathrm{mg} / \mathrm{kg}$ (high-dose group) on day 0 . Sequential $\left[{ }^{18} \mathrm{~F}\right] \mathrm{FDG}$ small-animal PET $(\mu \mathrm{PET})$ scans were performed on days $0,2,6,9,13$ and 16 after treatment. The mean and maximum standardized uptake value $\left(\mathrm{SUV}_{\text {mean }}\right.$ and $\left.\mathrm{SUV}_{\text {max }}\right)$, metabolic tumour volume $\left(\mathrm{Vol}_{\text {metab }}\right)$ and total lesion glycolysis (TLG) were calculated.

Results A significant decrease in $\left[{ }^{18} \mathrm{~F}\right] \mathrm{FDG}$ uptake was observed on day 2 in the medium-dose and high-dose groups and on day 6 in the low-dose group, all preceding morphological changes. $\mathrm{SUV}_{\text {mean }}$ and $\mathrm{SUV}_{\max }$ formed a plateau from day 6 to day 9 , corresponding to the known influx of inflammatory cells. No obvious plateau was observed with TLG which was found to be the most sensitive parameter clearly differentiating the low-dose group from the medium- and high-dose groups early after therapy. Conclusion $\left[{ }^{18} \mathrm{~F}\right] \mathrm{FDG}$ uptake was able to reflect the doseresponse relationship for cyclophosphamide. TLG was the best parameter for dose-related response assessment in this tumour model.

Keywords B-cell lymphoma · SCID mice.

Cyclophosphamide $\cdot$ Therapy response monitoring .

Molecular imaging $\cdot\left[{ }^{18} \mathrm{~F}\right] \mathrm{FDG}$ PET

\section{Introduction}

Lymphomas are highly sensitive to treatment with chemotherapy and radiotherapy and have substantial long-term 
cure rates. However, there are still a few patients who have resistant disease and early change of therapy can improve survival in these patients. On the other hand, long-term toxicity of the administered treatment is increasingly recognized, and in patients with chemosensitive disease, unnecessary treatment should be avoided. For these reasons, there is a strong need for tailoring the intensity of treatment to individual patients on the basis of early response assessment.

Early response assessment is difficult with conventional radiographic modalities because reduction in morphological tumour volume is only a late sign of effective therapy. Therefore, anatomic imaging modalities are less suitable for evaluation of early response assessment. Furthermore, they cannot distinguish between benign fibrotic scarring and persisting viable tumour tissue [1]. Several clinical studies have demonstrated the superiority of $\left[{ }^{18} \mathrm{~F}\right] \mathrm{FDG}$ PET imaging for initial staging of lymphoma, management of recurrent cancer and monitoring of therapy response [2-6].

To be a reliable predictor of response, changes in tumour $\left[{ }^{18} \mathrm{~F}\right]$ FDG uptake should reflect changes in the viable tumour cell fraction. However, the rapid decrease in tumour glucose metabolism after effective therapy is only partly concordant with uptake in viable tumour cells. A flare phenomenon has been described very early after chemotherapy which has been considered to be due to an increased metabolism of preapoptotic cells trying to repair DNA and requiring energy for apoptosis initiation [7, 8]. On the other hand chemotherapy and radiotherapy induce inflammation and $\left[{ }^{18} \mathrm{~F}\right] \mathrm{FDG}$ is highly accumulated in inflammatory cells, leading to an overestimation of the viable tumour fraction $[9,10]$. It has been shown that corticosteroid administration can suppress the $\left[{ }^{18} \mathrm{~F}\right] \mathrm{FDG}$ uptake caused by the inflammatory influx [11].

In this study we evaluated $\left[{ }^{18} \mathrm{~F}\right] \mathrm{FDG}$ uptake after the administration of different doses of cyclophosphamide to define a dose-response relationship and to demonstrate $\left[{ }^{18} \mathrm{~F}\right]$ FDG PET as a reliable tool for evaluating early therapy response.

\section{Materials and methods}

Animal model

Severe combined immune deficient (SCID) mice (C.B-17/ Icr scid/scid) were inoculated with cells of the Daudi B cell line, a human lymphoma cell line derived from a Burkitt lymphoma [10]. Mice were bred under germ-free conditions, and at 6 to 8 weeks of age were subcutaneously inoculated with 5 million Daudi cells in the right thigh. The developing tumours were measured twice a week using a calliper. When the developing tumours had reached a diameter of about $15 \mathrm{~mm}$, the mice were treated with a single dose of cyclophosphamide (day 0 ).

\section{Experimental design}

The mice were divided into four groups. The first group was not treated (four mice, control group). The other groups received cyclophosphamide on day 0 at doses of $75 \mathrm{mg} / \mathrm{kg}$ (low-dose group, five mice), $125 \mathrm{mg} / \mathrm{kg}$ (medium-dose group, five mice) and $175 \mathrm{mg} / \mathrm{kg}$ (high-dose group, four mice). Small-animal PET ( $\mu$ PET) scans were performed on day 0 (before treatment) and on days 2, 6, 9, 13 and 16 after the administration of cyclophosphamide. Tumour dimensions were measured at each time-point using a calliper and tumour volumes $\left(\mathrm{Vol}_{\text {calliper }}\right)$ were calculated using the equation: $\operatorname{Vol}_{\text {calliper }}(\mathrm{ml})=(\pi / 6) \times \mathrm{a} \times \mathrm{b} \times \mathrm{c} \times 10^{-3}$, where $\mathrm{a}, \mathrm{b}$ and $\mathrm{c}$ represent the three orthogonal dimensions of the tumour in millimetres.

\section{$\mu$ PET scanning}

After overnight fasting, $\mu$ PET scanning was performed using a Concorde Focus $\mu$ PET scanner (Knoxville, TN). The mice were sedated with isoflurane anaesthesia, and body weight and glycaemia were determined. Then 8 $11 \mathrm{MBq}\left[{ }^{18} \mathrm{~F}\right] \mathrm{FDG}$ was injected via a tail vein. $\mu$ PET imaging was performed $60 \mathrm{~min}$ after injection, $(10 \mathrm{~min}$ per frame), in a single bed position with the tumour in the centre of the view. A few minutes before scanning, the bladder was emptied to reduce reconstruction artefacts.

Parameters and statistical analysis

For each time-point, the mean standardized uptake value $\left(\mathrm{SUV}_{\text {mean }}\right)$, maximal SUV $\left(\mathrm{SUV}_{\max }\right)$ and the metabolic tumour volume $\left(\mathrm{Vol}_{\text {metab}}\right)$ in the different groups were measured with different absolute thresholds (SUV 1, 1.1, 1.2 and 1.3) and relative thresholds $(40 \%$ and $50 \%$ of $\left.\mathrm{SUV}_{\max }\right)$ to determine the most reliable threshold for volume contouring. Alternatively, inhouse software enabled visual volume contouring (3-D isocontour) [12]. When no remaining tumour was present on $\left[{ }^{18} \mathrm{~F}\right] \mathrm{FDG}$ PET images, we used $\mathrm{SUV}_{\text {mean }}$ of a standard region of interest at the previous location of the tumour. SUVs were automatically calculated using the formula: SUV $=$ measured activity concentration in the tumour $(\mathrm{Bq} / \mathrm{g}) \times$ body weight $(\mathrm{g}) /$ injected activity $(\mathrm{Bq})$. To correct for differences in administered dose (paravenous injections became more frequent after several injections), all SUV values were normalized by dividing the SUV of the tumour by the corresponding $\mathrm{SUV}_{\text {mean }}$ of a standard region in the liver [13]. 
Corrections for glycaemia could not add any information and showed a very high variation intra- and interindividually. This was possibly related to the very sensitive stress system. In human studies it is common to correct for glycaemia, but in our experience, correction for glycaemia in mice does not change the results but only adds more variability [11].

Total lesion glycolysis (TLG) was defined as $\mathrm{SUV}_{\text {mean }} \times$ $\mathrm{Vol}_{\text {metab. }}$. Decreases in TLG were calculated and expressed as percentage of the baseline scan on day 0: TLG \% decrease $=\left(\mathrm{TLG}_{x}-\mathrm{TLG}_{0}\right) / \mathrm{TLG}_{0} \times 100 \%$, where $\mathrm{TLG}_{x}$ is the $\left[{ }^{18} \mathrm{~F}\right] \mathrm{FDG}$ uptake on day $x$ (also called deltaTLG or Larson-Ginsberg Index) [14]. The percentage decreases in $\mathrm{SUV}_{\text {mean }}, \mathrm{SUV}_{\text {max }}$ and $\mathrm{Vol}_{\text {metab }}$ were calculated in an analogous way. Means and SEM (standard error of the mean) were calculated for the different parameters and are expressed graphically. Two-tailed $p$ values $\leq 0.05$ were considered statistically significant. Within each treatment group unpaired Student's $t$-tests were performed to evaluate changes over time. A Bonferroni correction was subsequently used and corrected $p$ values are reported as $p_{\text {corrected. To compare overall reductions between treatment }}$ groups over time, the areas under the curve (AUC) of the different $\left[{ }^{18} \mathrm{~F}\right] \mathrm{FDG}$ PET parameters were calculated and tested using an unpaired Student's $t$-test.

\section{Results}

Clinical effects and measurement by calliper

The global condition of the mice had deteriorated by 2 to 3 days after treatment. In particular, mice that had received $175 \mathrm{mg} / \mathrm{kg}$ cyclophosphamide became apathetic and their fur became dull, while the global condition of mice that had received $75 \mathrm{mg} / \mathrm{kg}$ was generally not affected. The clinically measured tumour volume ( $\left.\mathrm{Vol}_{\text {calliper }}\right)$ in the control group showed a persistent increase during followup, and the mean $\mathrm{Vol}_{\text {calliper }}$ increased from $0.82 \mathrm{ml}$ (range $0.54-1.27 \mathrm{ml}$ ) on day 0 to $2.60 \mathrm{ml}$ (range $1.86-3.85 \mathrm{ml}$ ) on day 16. In treated mice, a reduction in $\mathrm{Vol}_{\text {calliper }}$ was seen from day 6 in the mice in the medium-dose and high-dose groups ( $p<0.001$ and $p=0.004$, respectively), and from day 9 in the low-dose group $(p<0.001)$. These volume reductions were found to be significant after Bonferroni correction with a $p_{\text {corrected }}$ value of 0.01 . All clinically detectable tumour had almost disappeared from day 13 in the medium-dose and high-dose groups (Fig. 1a). The low-dose group showed regrowth on day 16 (Fig. 1a).

Thresholds for volume contouring

Different thresholds for adequate delineation of tumour volumes were evaluated. We used several absolute and relative thresholds and visually reviewed the corresponding volumes. Absolute thresholds were not effective for evaluation of therapy response in our tumour model as they often underestimated metabolic tumour volume, leading to negligible tumour volumes while visually important tumour tissue remained, especially late after therapy. Moreover, absolute thresholds are influenced by the effective injected dose and do not take into account paravenous injections (that occur more frequently after several scans) and other subject-dependent differences. Relative thresholds were also ineffective for tumour delineation as they were highly dependent on the $\mathrm{SUV}_{\max }$, leading to under- or overestimation of the tumour volume in different images. The same observation was made for thresholds that were a multiple of the $\mathrm{SUV}_{\text {mean }}$ in the liver ( $2 \times$ or $3 \times \mathrm{SUV}_{\text {mean }}$ of the liver). We therefore decided to use the visually based $3-\mathrm{D}$ isocontours. This technique gave visually satisfying results, was very easy to perform and was highly reproducible with only minor changes of $\mathrm{Vol}_{\text {metab }}$ when the final threshold was slightly altered.

\section{Response monitoring with $\left[{ }^{18} \mathrm{~F}\right] \mathrm{FDG}$ PET}

There was a fast and obvious response in $\mathrm{Vol}_{\text {metab }}$ and $\left[{ }^{18} \mathrm{~F}\right]$ FDG uptake after chemotherapy (Fig. 1b). The mean $\mathrm{Vol}_{\text {metab }}$ of the primary tumours of the treated groups (day 0) was $2.8 \mathrm{ml}$ (range $1 \mathrm{ml}$ to $-6.2 \mathrm{ml}$ ) and of the control group was $2.2 \mathrm{ml}$ (range 1.3 to $3.2 \mathrm{ml}$ ). Vol metab $_{\text {mogressively increased }}$ in the control group during follow-up. In contrast, $\mathrm{Vol}_{\text {metab }}$ decreased from day 6 onwards in all treated groups, with a faster and more pronounced decrease with increasing administered dose. This decrease in $\mathrm{Vol}_{\text {metab }}$ occurred earlier after treatment and showed less variability between mice than the decrease in $\mathrm{Vol}_{\text {calliper }}$ (Fig. 1). In the low-dose group $\mathrm{Vol}_{\text {metab }}$ showed an increase after 16 days of treatment.

Concerning $\mathrm{SUV}_{\text {mean }}$, control mice showed a marked fluctuation corresponding to visual changes in central necrosis (Fig. 3a). On day 2 a decrease was seen in the medium-dose group (Fig. 2) and in the high-dose group $(-31 \pm 4 \%$ and $-18 \pm 4 \%$, respectively; Fig. 3a). On day 6 all treatment groups showed a decrease in $\mathrm{SUV}_{\text {mean }}(-35 \pm 3 \%$, $-58 \pm 3 \%$ and $-42 \pm 5 \%$ in the low-, medium- and high-dose groups, respectively) after which a plateau in $\mathrm{SUV}_{\text {mean }}$ was seen between day 6 and day 9 . The height of this plateau was dose dependent. The AUC $\Delta \mathrm{SUV}_{\text {mean }}$ in the low-dose group was significantly lower than in the medium- and high-dose groups ( $p=0.002$ and $p=0.02$, respectively). The AUC $\triangle \mathrm{SUV}_{\text {mean }}$ was not significantly different between the medium- and high-dose groups. From day $9 \mathrm{SUV}_{\text {mean }}$ decreased further in the medium- and high-dose groups ( $-62 \pm 8 \%$ and $-71 \pm 12 \%$ on day 16 , respectively). The lowdose group on the other hand showed an increase in $\mathrm{SUV}_{\text {mean }}$ from day $13(-10 \pm 13 \%$ on day 16$)$. 

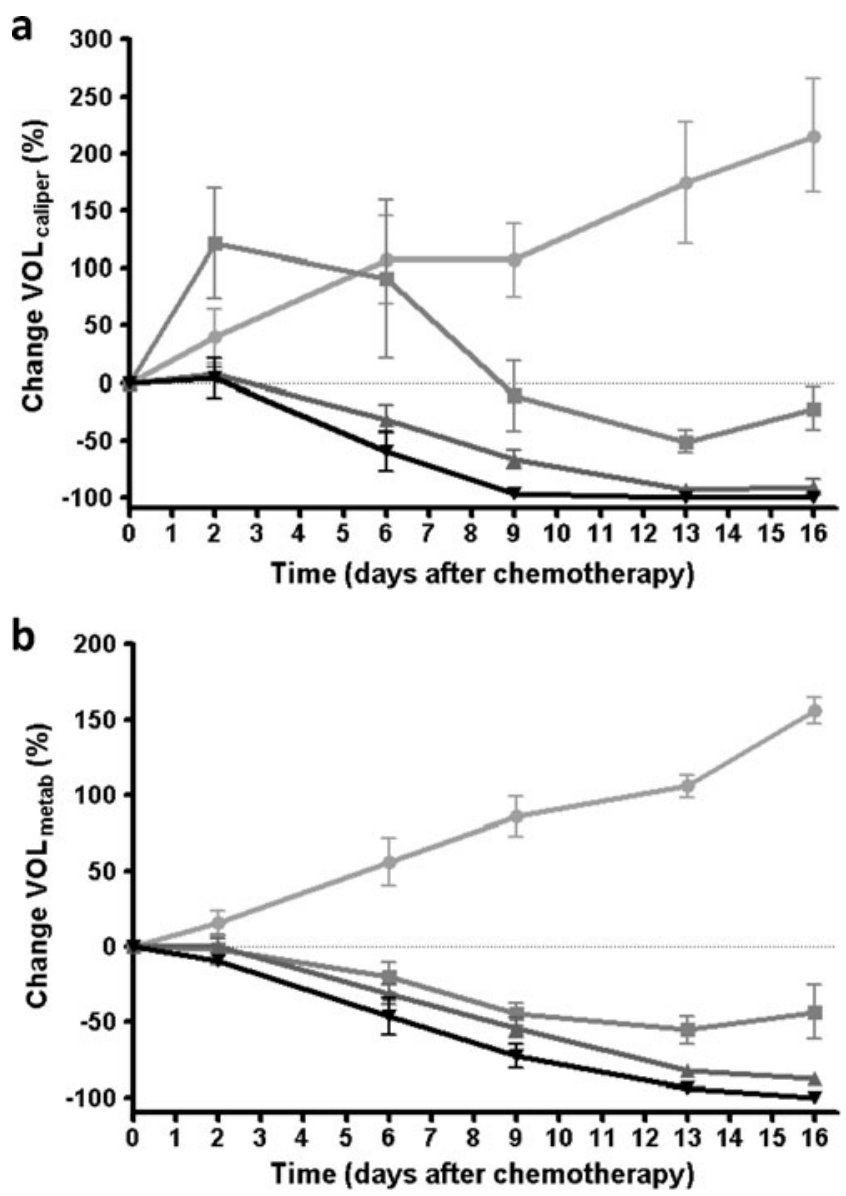

$\leftarrow$ Control $=75 \mathrm{mg} / \mathrm{kg} \neq 125 \mathrm{mg} / \mathrm{kg} \neq 175 \mathrm{mg} / \mathrm{kg}$

Fig. 1 Changes in $\mathrm{Vol}_{\text {calliper }}$ (tumor volume measured by calliper) (a) and $\mathrm{Vol}_{\text {metab }}$ (metabolic volume measured by $\left[{ }^{18} \mathrm{~F}\right] \mathrm{FDG}$ PET) (b) during follow-up in control mice and mice treated with 75, 125 and $175 \mathrm{mg} / \mathrm{kg}$ cyclophosphamide. The data presented are mean $( \pm \mathrm{SEM})$ percentage changes in relation to the reference volumes on day 0 before therapy

$\mathrm{SUV}_{\max }$ showed a similar progression over time (Fig. 3b) with a fast decrease seen on day 2 in the medium-dose group ( $-42 \pm 4 \%)$ and in the high-dose group $(-18 \pm 7 \%)$ and a significant decrease for the low-dose group on day $6(-25.6 \pm 9 \%)$. Again a plateau was observed from day 6 to day 9, after which the $\mathrm{SUV}_{\max }$ in the medium- and high-dose groups showed a further decrease ( $-66 \pm 8 \%$ and $-78 \pm 13 \%$ respectively) on day 16 while the low-dose group showed an increase in $\mathrm{SUV}_{\max }$ from day 13 with a value of $-13 \pm 16 \%$ on day 16 . Overall the different treatment groups did not show a significantly different AUC $\triangle S_{U V}$ max which might have been due to the slightly higher variability of the $\mathrm{SUV}_{\text {max }}$ measurement compared to the $\mathrm{SUV}_{\text {mean }}$.

In contrast to $\mathrm{SUV}_{\text {mean }}$ and $\mathrm{SUV}_{\max }$, TLG showed more pronounced differences between the control and treated groups. Moreover, the TLG response was less variable between the treatment groups (Fig. 4). The control group showed a gradual increase in TLG and on day 16 TLG was about four times the reference value. The TLG in the medium- and high-dose groups showed a significant decrease 2 days after treatment $(-31 \pm 3 \%$ and $-25 \pm 2 \%$, respectively). In the low-dose group TLG showed a significant decrease on day $6(-42 \pm 7 \%)$, which was significantly less pronounced than in the medium- and high-dose groups on day $6(-72 \pm 3 \%$ and $-71 \pm 3 \%$, respectively). The high dose $(175 \mathrm{mg} / \mathrm{kg})$ provided no extra benefit over the medium dose $(125 \mathrm{mg} / \mathrm{kg})$. This was confirmed by the AUC $\triangle \mathrm{TLG}$ which was significantly lower in the low-dose group than in the medium- and high-dose groups $(p=0.03$ and $p=0.04$, respectively). From day 6 TLG showed a further decrease in all treatment groups. TLG showed an increase in the lowdose group from day 13 to day 16 .

\section{Discussion}

Several studies have shown that $\left[{ }^{18} \mathrm{~F}\right] \mathrm{FDG}$ PET is a useful technique for evaluating tumour response to chemotherapy, and that changes in $\left[{ }^{18} \mathrm{~F}\right] \mathrm{FDG}$ uptake appear sooner and are more accurate than changes in morphological tumour volume [2-4, 15]. However, it remains unclear which factors play a role in changing glucose metabolism shortly after chemotherapy and what is the optimal method for quantification of tumour response [7-10]. We therefore evaluated $\left[{ }^{18} \mathrm{~F}\right] \mathrm{FDG}$ uptake in a lymphoma animal model after administration of different doses of cyclophosphamide with the aim of defining the dose-response relationship. PET scans were analysed and SUVs were used for quantitative assessment of tumour glucose metabolism. Standardized protocols for SUV measurement were shown to be reproducible and highly accurate for evaluating response to chemotherapy [16-18]. We also evaluated response to therapy in terms of volumetric changes in the tumour measured using a calliper, as several studies have shown a good correlation between calliper measurements and the tumour volume [19, 20]. This method was easy, fast, inexpensive and in comparison to CT or MRI does not require anaesthesia, scan time or image analysis. However, errors can occur due to variability in tumour shape, skin thickness and subcutaneous fat layers. In our study relative changes in calliper measurements were used to express response to therapy. Therefore, differences in tumour shape, skin thickness, subcutaneous fat layer and tumour compressibility would not have had a great influence on the data. Additionally the measurements were always performed by the same person to reduce the interobserver variability. As a result, the variations in our measurements were acceptable. Only for the control group and the low-dose group did the data show more pronounced variability. 


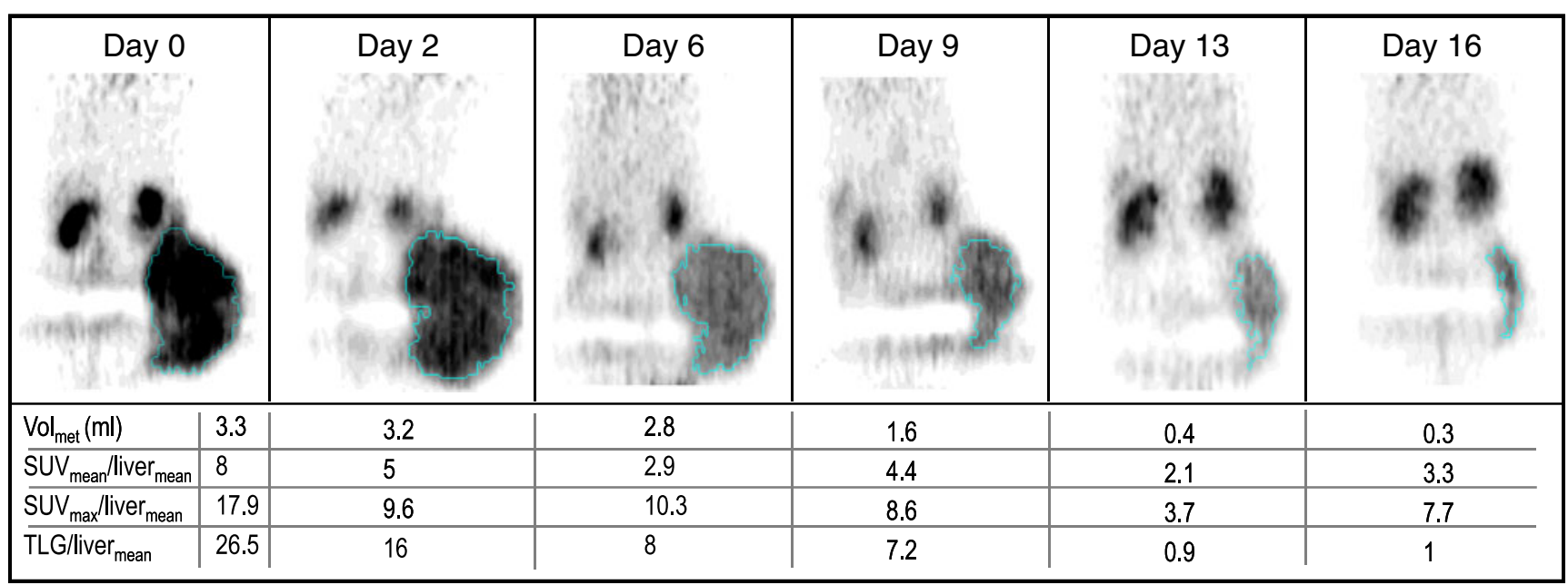

Fig. 2 Follow-up scans (days 0, 2, 6, 9, 13 and 16) in the same mouse treated with $125 \mathrm{mg} / \mathrm{kg}$ cyclophosphamide on day 0 . The corresponding values of $\mathrm{Vol}_{\text {metab }}\left(V_{o l} l_{\text {met }}\right), \mathrm{SUV}_{\text {mean }} /$ liver $_{\text {mean }}, \mathrm{SUV}_{\text {max }} /$ liver $_{\text {mean }}, \mathrm{TLG} /$ liver $_{\text {mean }}$ measured in the same mouse are shown for each time-point
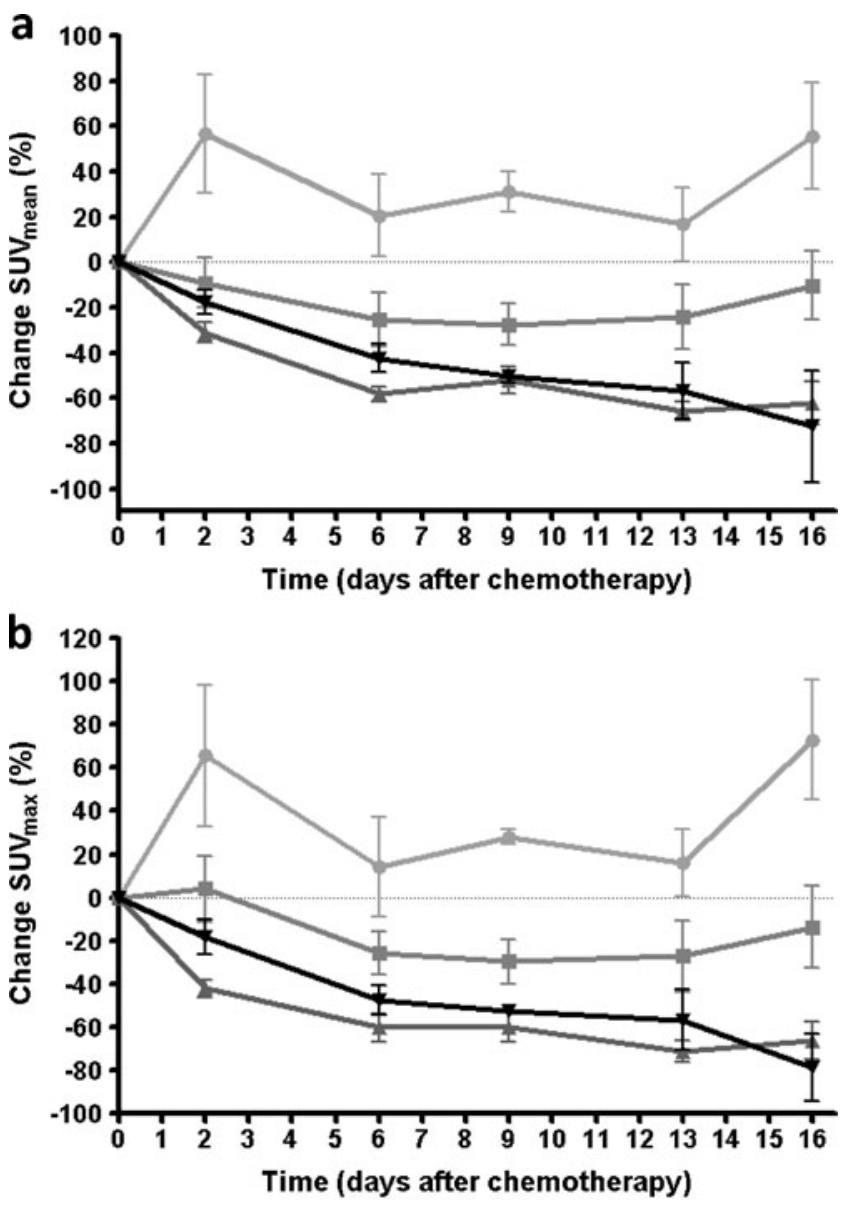

Control $=75 \mathrm{mg} / \mathrm{kg} \neq 125 \mathrm{mg} / \mathrm{kg} \neq 175 \mathrm{mg} / \mathrm{kg}$

Fig. 3 Changes in $\mathrm{SUV}_{\text {mean }}$ (a) and $\mathrm{SUV}_{\text {max }}(\mathbf{b})$ during follow-up in control mice and mice treated with 75,125 and $175 \mathrm{mg} / \mathrm{kg}$ cyclophosphamide. The data presented are mean $( \pm$ SEM) percentage changes in relation to the reference values on day 0 before therapy
However, these fluctuations were also observed for $\mathrm{SUV}_{\text {mean }}$ and $\mathrm{SUV}_{\max }$ and in the control group this could have been due to changes in central necrosis. Although variations in the calliper measurements were minimized in this study, CT and MRI are known to be more accurate and reliable for the assessment of morphological changes [21]. However, the ready availability of morphological imaging tools as well as the whole-body irradiation from repeated CT measurements, potentially impacting the results, led to the current protocol. Furthermore, the longer anaesthesia protocols necessary for MRI imaging also increase potential drop-outs. In conclusion, the calliper measurement was the most feasible approach for the current protocol.

Our first goal was to define an optimal way to delineate metabolic volume and quantify therapy response. Visual evaluation of different thresholds in our study showed that neither absolute nor relative thresholds $(40 \%$ and $50 \%$ $\left.\mathrm{SUV}_{\max }\right)$ were able to adequately identify residual tumour tissue after chemotherapy, and that every threshold used should be compared with (and adapted to) the visual interpretation of the acquired images. These findings correspond with the findings of Nestle et al. who compared different techniques for metabolic tumour contour delineation and found substantially different volumes, especially in tumours with inhomogeneous uptake [22]. We used two different methods for the definition of the minimal SUV threshold ( $\left.\mathrm{SUV}_{\text {threshold }}\right)$ previously described in the literature $[22,23]$. These approaches were not applicable in our tumour model because of important overestimation of tumour volumes after treatment. Further investigation of our dataset could reveal an appropriate standardized threshold in our tumour model, but this would probably not be applicable to image analysis in humans. 


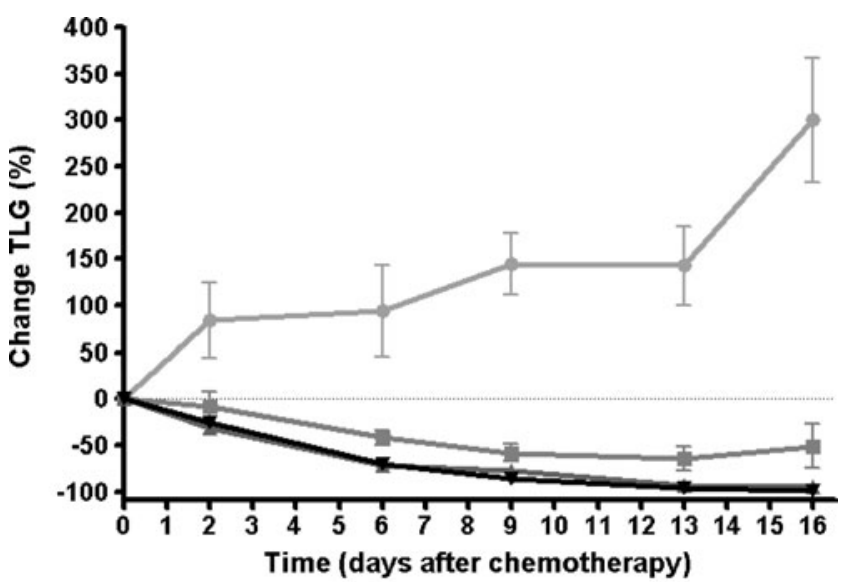

$\leadsto$ Control $=75 \mathrm{mg} / \mathrm{kg} \neq 125 \mathrm{mg} / \mathrm{kg} \neq 175 \mathrm{mg} / \mathrm{kg}$

Fig. 4 Changes in TLG during follow-up in control mice and mice treated with 75,125 and $175 \mathrm{mg} / \mathrm{kg}$ cyclophosphamide. The data presented are mean $( \pm$ SEM) percentage changes in TLG in relation to the reference TLG on day 0 before therapy

Despite the implementation of standardized approaches, there were important differences in tumour size and characteristics between individuals, underlining the need to use comparative values (percentage reduction) instead of absolute quantitative parameters. Correction for injection problems (e.g. paravenous injection after several scans) by using the liver uptake as a reference was necessary [13]. Correction for glycaemia proved not to be useful in the current study, since it led to a higher variability in SUVs without significantly changing the mean values or the pattern of the curve. Moreover, below a certain level, elevated glycaemia might not have an effect on $\left[{ }^{18} \mathrm{~F}\right] \mathrm{FDG}$ uptake in inflammatory cells while it may have an effect in malignant cells, which makes distinguishing different cell fractions even more complicated [23].

Changes in PET parameters occurred earlier than changes in clinically measured tumour volume and showed less inter- and intraobserver variability, and therefore PET was more suitable for evaluation of response assessment. A significant decrease in $\mathrm{SUV}_{\text {mean }}$ was measured as early as 2 days after chemotherapy. This was in contrast to the "metabolic flare" observed early after therapy in other studies [7]. We speculate that the tumour cell line we used is less sensitive to this effect than those used by others, possibly because of minimized or delayed energy demand for repair mechanisms. Following the early decrease in $\left[{ }^{18} \mathrm{~F}\right] \mathrm{FDG}$ uptake, we observed a plateau in FDG uptake between day 6 and day 9 . This stabilization results from the fact that SUVs are not only a result of $\left[{ }^{18} \mathrm{~F}\right] \mathrm{FDG}$ uptake by viable tumour cells, but also of $\left[{ }^{18} \mathrm{~F}\right] \mathrm{FDG}$ uptake in inflammatory mouse cells, which occurs temporarily with effective therapy [11]. It has been demonstrated that approximately $30 \%$ of total $\left[{ }^{18} \mathrm{~F}\right] \mathrm{FDG}$ uptake can be attributed to nontumoral tissues and that relative uptake in inflammatory cells can be even higher than in viable tumour cells [9]. A previous study by our group has shown that corticosteroids can decrease the contribution of inflammatory cells to $\left[{ }^{18} \mathrm{~F}\right] \mathrm{FDG}$ uptake [11]. The administration of cyclophosphamide resulted in a steady reduction of the viable tumour cell fraction. On day 9 after treatment a clear increase in the amount of stromal cells (mainly macrophages) was measured. These results were obtained in the same animal model (after administration of $125 \mathrm{mg}$ / $\mathrm{kg}$ cyclophosphamide) corresponding to the medium-dose group of the current study. Therefore the $\mathrm{SUV}_{\text {mean }}$ plateau measured between day 6 and day 9 does not reflect stabilization of the amount of viable tumour cells, but represents $\left[{ }^{18} \mathrm{~F}\right] \mathrm{FDG}$ uptake in both inflammatory and malignant cells. As a similar plateau was observed in both the low- and high-dose groups, we can assume that the same influx of inflammatory cells occurred, and that the remaining differential effects were solely due to the different doses of cyclophosphamide.

These results cannot be generalized to immunocompetent animals or humans because immunodeficient mice have a suppressed T- and B-cell compartment. Despite these limitations, these mice have a normal macrophage, granulocyte and T-cell function, and previous studies have demonstrated the invasion of stromal cells leading to an inflammatory reaction after treatment [11]. Our hypothesis is that the effect in immunocompetent mice will be more dramatic, because of a more sustained inflammatory response, but the conclusion will be generally the same. To the best of our knowledge, no immune-competent lymphoma mouse model had been described at the time we set up our experiments. The recent introduction of syngeneic mouse models opens new perspectives in the study of the interactions between inflammatory cells and tumour cells in immune-competent animals. These interactions and their effect on $\left[{ }^{18} \mathrm{~F}\right] \mathrm{FDG}$ uptake after therapy are certainly worth studying in the future. However, metabolic imaging in immune-suppressed animals will always remain valuable because the current developments towards new therapies, addressing specific molecular targets, will continue to require the study of human cell lines in vivo.

To determine the optimal parameter for therapy response, we compared several semiquantitative PET parameters in the different treatment groups. SUV $\mathrm{max}_{\max }$ showed a similar pattern to normalized $\mathrm{SUV}_{\text {mean }}$, although variability in $\mathrm{SUV}_{\max }$ was larger. The major advantage of $\mathrm{SUV}_{\max }$ is its independence from the threshold used for lesion contouring and its resistance to interobserver variability. A different pattern was observed with the TLG parameter which showed a persisting decrease in metabolic volume. 
This parameter most clearly distinguished control from treated mice. Moreover, early after treatment TLG was already able to differentiate the low-dose group from the medium- and high-dose group. This suggests that quantification of tumour response after therapy is more reliable using decreases in TLG than decreases in $\mathrm{SUV}_{\text {mean }}$ or $\mathrm{SUV}_{\text {max }}$. It has already been reported that decreases in TLG are more likely to demonstrate relevant changes than decreases in $\mathrm{SUV}_{\text {max }}$ or $\mathrm{SUV}_{\text {mean }}$ [14]. The plateau of $\mathrm{SUV}_{\text {mean }}$, as well as the decrease in TLG and $\mathrm{Vol}_{\text {metab }}$, was dose-dependent, although no additional effect was seen as a result of increasing the dose from $125 \mathrm{mg} / \mathrm{kg}$ to $175 \mathrm{mg} / \mathrm{kg}$, suggesting that there is no additional value in administering cyclophosphamide at doses higher than $125 \mathrm{mg} / \mathrm{kg}$. This correlates with the finding of Meyn et al. that the proportion of apoptotic cells reaches a plateau at doses higher than $100 \mathrm{mg} / \mathrm{kg}$ [24]. It is remarkable that the observed plateau for $\mathrm{SUV}_{\text {mean }}$ and $\mathrm{SUV}_{\text {max }}$ was slightly higher in the $175 \mathrm{mg} / \mathrm{kg}$ dose group than in the $125 \mathrm{mg} / \mathrm{kg}$ dose group. This could have been a sampling artefact, as it was not statistically significant $(p=0.056)$, but could also point to a more complex mechanism that provoked a higher necrotic cell fraction in comparison to the apoptotic cell fraction inducing a more pronounced influx of inflammatory cells. Kaledin et al. emphasize the complexity of the mechanism of action of cyclophosphamide and its metabolites in inducing apoptosis and/or necrosis with increasing doses [25].

The low-dose group showed increasing SUVs, increasing metabolic volume and increasing TLG in late stages after therapy (day 16) indicating regrowth of the tumour. This suggests that a dose of $75 \mathrm{mg} / \mathrm{kg}$ is not sufficient to achieve tumour control and that $\left[{ }^{18} \mathrm{~F}\right] \mathrm{FDG}$ PET correlates with tumour relapse.

A change in $\left[{ }^{18} \mathrm{~F}\right] \mathrm{FDG}$ tumour uptake of more than $20 \%$ SUV has been suggested as a cut-off value that will reduce measurement errors and take into account spontaneous fluctuations in tumour metabolic activity [26]. In lymphoma the clinical question is not whether there is an initial response to therapy but whether the response is sufficient to cure the patient. For example, if there is a major decrease in $\left[{ }^{18} \mathrm{~F}\right] \mathrm{FDG}$ uptake in a certain tumour part accompanied by a chemoresistant focus, the uptake in this focus is relevant for the clinician and crucial for patient outcome. Consequently, the best PET parameter predicting relapse is the $\mathrm{SUV}_{\max }$ of the resistant tumour clone. However, in most patients with a solid tumour, or after several relapses, the main aim is not to attain a disease-free status, but to achieve a response to the instituted therapy that prolongs survival and keeps the disease temporarily under control. In this setting, measuring a parameter reflecting the whole tumour volume is more logical (TLG, $\mathrm{SUV}$ mean or $\mathrm{Vol}_{\text {metab}}$ ).

\section{References}

1. Weber WA. Use of PET for monitoring cancer therapy and for predicting outcome. J Nucl Med 2005;46(6):983-95.

2. Brepoels L, Stroobants S, De Wever W, et al. Aggressive and indolent non-Hodgkin's lymphoma: response assessment by integrated international workshop criteria. Leuk Lymphoma 2007;48(8):1522-30.

3. Brepoels L, Stroobants S, De Wever W, et al. Hodgkin lymphoma: response assessment by revised International Workshop Criteria. Leuk Lymphoma 2007;48(8):1539-47.

4. Spaepen K, Stroobants S, Dupont P, et al. Early restaging positron emission tomography with (18)F-fluorodeoxyglucose predicts outcome in patients with aggressive non-Hodgkin's lymphoma. Ann Oncol 2002;13(9):1356-63.

5. Juweid ME, Cheson BD. Positron-emission tomography and assessment of cancer therapy. N Engl J Med 2006;354(5):496507.

6. Zinzani PL, Stefoni V, Tani M, et al. Role of [18F]fluorodeoxyglucose positron emission tomography scan in the follow-up of lymphoma. J Clin Oncol 2009;27(11):1781-7.

7. Aide N, Poulain L, Briand M, et al. Early evaluation of the effects of chemotherapy with longitudinal FDG small-animal PET in human testicular cancer xenografts: early flare response does not reflect refractory disease. Eur J Nucl Med Mol Imaging 2009;36 (3):396-405.

8. Kostakoglu L, Goldsmith SJ. 18F-FDG PET evaluation of the response to therapy for lymphoma and for breast, lung, and colorectal carcinoma. J Nucl Med 2003;44(2):224-39.

9. Kubota R, Yamada S, Kubota K, Ishiwata K, Tamahashi N, Ido T. Intratumoral distribution of fluorine-18-fluorodeoxyglucose in vivo: high accumulation in macrophages and granulation tissues studied by microautoradiography. J Nucl Med 1992;33(11):197280.

10. Spaepen K, Stroobants S, Dupont P, et al. [(18)F]FDG PET monitoring of tumour response to chemotherapy: does [(18)F] FDG uptake correlate with the viable tumour cell fraction? Eur J Nucl Med Mol Imaging 2003;30(5):682-8.

11. Brepoels L, Stroobants S, Vandenberghe P, et al. Effect of corticosteroids on 18F-FDG uptake in tumor lesions after chemotherapy. J Nucl Med 2007;48(3):390-7.

12. Krak NC, Boellaard R, Hoekstra OS, Twisk JW, Hoekstra CJ, Lammertsma AA. Effects of ROI definition and reconstruction method on quantitative outcome and applicability in a response monitoring trial. Eur J Nucl Med Mol Imaging 2005;32(3):294301.

13. Leyton J, Latigo JR, Perumal M, Dhaliwal H, He Q, Aboagye EO. Early detection of tumor response to chemotherapy by $3^{\prime}$-deoxy$3^{\prime}-[18 \mathrm{~F}]$ fluorothymidine positron emission tomography: the effect of cisplatin on a fibrosarcoma tumor model in vivo. Cancer Res 2005;65(10):4202-10.

14. Larson SM, Erdi Y, Akhurst T, et al. Tumor treatment response based on visual and quantitative changes in global tumor glycolysis using PET-FDG imaging. The visual response score and the change in total lesion glycolysis. Clin Positron Imaging 1999;2(3):159-71.

15. Kostakoglu L, Agress Jr H, Goldsmith SJ. Clinical role of FDG PET in evaluation of cancer patients. Radiographics 2003;23 (2):315-40.

16. Stahl A, Ott K, Schwaiger M, Weber WA. Comparison of different SUV-based methods for monitoring cytotoxic therapy with FDG PET. Eur J Nucl Med Mol Imaging 2004;31(11):1471-8.

17. de Geus-Oei LF, van der Heijden HF, Visser EP, et al. Chemotherapy response evaluation with $18 \mathrm{~F}-\mathrm{FDG}$ PET in patients with non-small cell lung cancer. J Nucl Med 2007;48(10):1592-8. 
18. Weber WA, Petersen V, Schmidt B, et al. Positron emission tomography in non-small-cell lung cancer: prediction of response to chemotherapy by quantitative assessment of glucose use. J Clin Oncol 2003;21(14):2651-7.

19. Euhus DM, Hudd C, LaRegina MC, Johnson FE. Tumor measurement in the nude mouse. J Surg Oncol 1986;31(4):22934.

20. Tomayko MM, Reynolds CP. Determination of subcutaneous tumor size in athymic (nude) mice. Cancer Chemother Pharmacol 1989;24(3):148-54.

21. Jensen MM, Jorgensen JT, Binderup T, Kjaer A. Tumor volume in subcutaneous mouse xenografts measured by microCT is more accurate and reproducible than determined by $18 \mathrm{~F}-\mathrm{FDG}-$ microPET or external caliper. BMC Med Imaging 2008;8:16.

22. Nestle U, Kremp S, Schaefer-Schuler A, et al. Comparison of different methods for delineation of 18F-FDG PET-positive tissue for target volume definition in radiotherapy of patients with nonSmall cell lung cancer. J Nucl Med 2005;46(8):1342-8.

23. Zhuang HM, Cortes-Blanco A, Pourdehnad M, et al. Do high glucose levels have differential effect on FDG uptake in inflammatory and malignant disorders? Nucl Med Commun 2001;22(10):1123-8.

24. Meyn RE, Stephens LC, Hunter NR, Milas L. Induction of apoptosis in murine tumors by cyclophosphamide. Cancer Chemother Pharmacol 1994;33(5):410-4.

25. Kaledin VI, Nikolin VP, Galyamova MR, Vasil'eva ED, Baimak TY, Popova NA. High apoptosis-inducing and antitumor activities of the products of biological but not chemical cyclophosphamide activation. Dokl Biol Sci 2002;386:426-9.

26. Lorenzen M, Wedegartner U, Weber C, Petersen JP, Adam G, Lorenzen J. Clinical relevance of multislice CT of the spine after osteosynthesis. Rofo 2005;177(11):1540-4. 